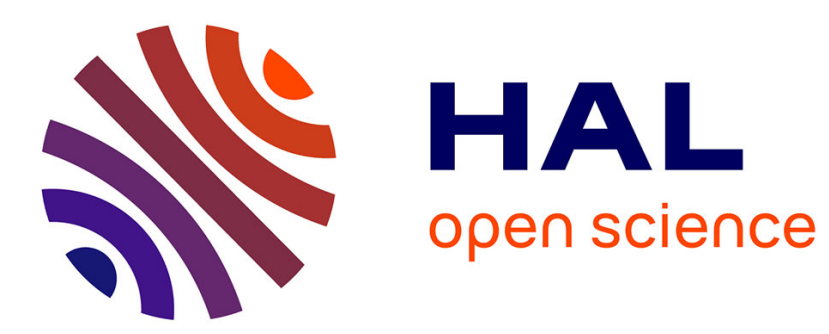

\title{
Overview and First Results of the Montreal Urban Snow Experiment 2005
}

A. Lemonsu, S. Bélair, J. Mailhot, M. Benjamin, F. Chagnon, G. Morneau, B. Harvey, James A. Voogt, M. Jean

\section{- To cite this version:}

A. Lemonsu, S. Bélair, J. Mailhot, M. Benjamin, F. Chagnon, et al.. Overview and First Results of the Montreal Urban Snow Experiment 2005. Journal of Applied Meteorology and Climatology, 2008, 47 (1), pp.59-75. 10.1175/2007JAMC1639.1 . hal-02369069

\section{HAL Id: hal-02369069 \\ https://hal.science/hal-02369069}

Submitted on 18 Nov 2019

HAL is a multi-disciplinary open access archive for the deposit and dissemination of scientific research documents, whether they are published or not. The documents may come from teaching and research institutions in France or abroad, or from public or private research centers.
L'archive ouverte pluridisciplinaire HAL, est destinée au dépôt et à la diffusion de documents scientifiques de niveau recherche, publiés ou non, émanant des établissements d'enseignement et de recherche français ou étrangers, des laboratoires publics ou privés. 


\title{
Overview and First Results of the Montreal Urban Snow Experiment 2005
}

\author{
A. Lemonsu,* S. Bélair, * J. Mailhot, ${ }^{*}$ M. Benjamin, ${ }^{+}$F. Chagnon, ${ }^{\#}$ G. Morneau, ${ }^{+}$B. Harvey, ${ }^{+}$ \\ J. VOOGT, ${ }^{\circledR}$ AND M. JEAN\# \\ * Meteorological Research Division, Environment Canada, Dorval, Quebec, Canada \\ + Quebec Region, Environment Canada, Montreal, Quebec, Canada \\ \# Canadian Meteorological Centre, Environment Canada, Dorval, \\ Quebec, Canada \\ @ University of Western Ontario, London, Ontario, Canada
}

(Manuscript received 7 November 2006, in final form 25 April 2007)

\begin{abstract}
Within the framework of a large urban meteorology program recently launched in Canada, the Montreal Urban Snow Experiment (MUSE) campaign has been conducted in order to document the thermoradiative exchanges in a densely built-up area of Montreal in late winter and spring conditions. The targeted period is of particular scientific interest because it covers the transition period from a mainly snow-covered urban environment to a mainly snow-free environment. The campaign is based on four weeks of observations from 17 March to 14 April 2005. It couples automatic and continuous measurements of radiation and turbulent fluxes, radiative surface temperatures, and air temperature and humidity with manual observations performed during intensive observation periods to supplement the surface temperature observations and to characterize the snow properties. The footprints of radiation and turbulent flux measurements are computed using the surface-sensor-sun urban model and the flux-source area model, respectively. The analysis of the radiometer footprint underscores the difficulty of correctly locating this type of instrument in urban environments, so that the sensor sees a representative combination of the urban and nonurban surfaces. Here, the alley contribution to the upward radiation tends to be overestimated to the detriment of the road contribution. The turbulent footprints cover homogeneous zones in terms of surface characteristics, whatever the wind direction. The initial analysis of the energy balance displays the predominance of the residual term $\left(Q_{\mathrm{Res}}=Q^{*}-Q_{H}-Q_{E}\right)$ in comparison with the turbulent sensible $\left(Q_{H}\right)$ and latent $\left(Q_{E}\right)$ heat fluxes, since its daytime contribution exceeds $50 \%$ of the net radiation $\left(Q^{*}\right)$. The investigation of energy balances observed at the beginning and at the end of the experiment (i.e., with and without snow) also indicates that the snow plays a significant role in the flux partitioning and the daily pattern of fluxes. Without snow, the energy balance is characteristic of energy balances that have been already observed in densely built-up areas, notably because of the hysteresis observed for $Q_{\text {Res }}$ and $Q_{H}$ in relation to $Q^{*}$ and because of the high contribution of $Q_{\mathrm{Res}}$, which includes the effect of heat storage inside the urban structures. With snow, the flux partitioning is modified by the snowmelt process leading to contributions of the residual term and latent heat flux, which are larger than in the case without snow to the detriment of the sensible heat flux.
\end{abstract}

\section{Introduction}

The measurements of meteorological variables, as well as energy and radiative exchanges in urban environments, are a real challenge and require specific experimental protocols that lead to important technical

Corresponding author address: Dr. A. Lemonsu, Météo-France, Centre National de Recherches Météorologiques, 42 avenue G. Coriolis, 31057 Toulouse CEDEX, France.

E-mail: aude.lemonsu@meteo.fr constraints. Over the last $10 \mathrm{yr}$, numerous observational campaigns were conducted in various urban environments such as city centers in Mexico City, Mexico (Oke et al. 1999), and Marseille, France (Grimmond et al. 2004a); residential districts in Chicago, Illinois, Los Angeles, California, Sacramento, California, Tucson, Arizona (Grimmond and Oke 1995), Oklahoma City, Oklahoma (Grimmond et al. 2004b), and Ouagadougou, Burkina Faso (Offerle et al. 2005); and industrial areas in Vancouver, British Columbia, Canada (Grimmond and Oke 1999b). The data collected during 
these field experiments allow the variability of the urban canopy processes for various urban landscapes and various built-up densities to be characterized. In addition to the urban environment, the meteorological conditions also influence the energy and radiative exchanges. To document the seasonal variability of these processes, several long-term observational studies were carried out in Toulouse, France (Masson et al. 2004), Basel, Switzerland (Rotach et al. 2005), Łódź, Poland (Offerle et al. 2006), and Melbourne, Australia (Coutts et al. 2007).

Very few experimental studies, however, have closely examined urban canopy processes in cold conditions, and more particularly with the presence of snow. During winter and in high-latitude cities, radiation, energy, and water balances can be even more complex because of the presence of snow on roofs, sidewalks, and roadways. For instance, snow cover modifies the albedo and directly affects net radiation. Furthermore, the evolution of temperature and water content of the snowpack also influences the turbulent fluxes. Some hydrological studies have documented the snow in urban environments (Ho and Valeo 2005), as well as urban snowmelt and urban flow rates. These studies pointed out the impact of snowmelt during springtime floods (Thorolfsson and Brandt 1996; Semádeni-Davies and Bengtsson 1998). Nevertheless, the radiative and energetic processes and the meteorological implications remain to be studied experimentally. To our knowledge, only the Basel and Łódź long-term experiments provide radiation and energy flux observations for winter and snowy episodes. But no characterization of the snow cover in the local environment of the flux stations has been done, which makes difficult or even impossible the evaluation of the impact of snow on flux measurements.

To at least partially remedy this lack of scientific understanding, and because of the cold nature of the Canadian winter climate, special emphasis is placed in the urban research program of the Meteorological Service of Canada (MSC) on the representation and understanding of snow processes and their influence on radiative and energetic exchanges in urban areas. In the context of this effort, the Montreal Urban Snow Experiment (MUSE; see also Bélair et al. 2006 for a brief overview) has been conducted by the MSC to document the evolution of the surface characteristics as well as the radiation and energy balances in a homogeneous dense urban area of Montreal, Quebec, Canada, during the winter-spring transition (from March to April 2005). The experiment's focus is on the analysis of urban surfaces and elements in a densely built-up district where vegetation cover is minimized. For this kind of homogeneous urban landscape, the main objectives of MUSE are to 1) study the evolution of snow cover during the winter-spring transition period, that is, from a near-total to a nonexistent snow cover; 2) assess the impact of snow on the surface energy and water fluxes; and 3) quantify the anthropogenic heat fluxes in late winter and spring conditions. The documentation of snow properties on roofs, roads, alleys, and sidewalks, and of anthropogenic heat and humidity releases in the district, are very important to make understanding and interpretation of radiation and energy balances possible.

This paper gives an overview of the experimental campaign and analyzes the continuous measurements of energy and radiation balances by focusing on the first two objectives of the campaign mentioned above. After a description of the urban area chosen for the experiment (section 2), section 3 presents the instrumentation and the continuous measurements supplemented by manual sampling of some variables during intensive observation periods (IOPs). Both radiation and turbulent flux footprints are investigated in section 4 , followed by the presentation of first results of radiation and energy balances (section 5).

\section{Selection of the observation site}

The city of Montreal $\left(45.5^{\circ} \mathrm{N}, 73.58^{\circ} \mathrm{W}\right)$ is the second largest Canadian city. It is part of the Montreal Island (Fig. 1), which counts more than 1800000 inhabitants. Located close to the Atlantic coast, the area is representative of eastern Canada winter climate, with relatively cold winters (mean daily temperatures from $-10.3^{\circ}$ to $-2.4^{\circ} \mathrm{C}$ between January and March) and a significant accumulation of snow $\left(2.14 \mathrm{~m} \mathrm{yr}^{-1}\right)$.

A single observation site was instrumented during MUSE to document the radiative and energetic exchanges. The instrumentation for this site was installed in an urban climate zone (UCZ) as homogeneously as possible, to avoid anomalies that could affect the radiative and turbulent measurements (Oke 2004). In the case of Montreal, the major sources of dynamic and energetic perturbations are Mont Royal in the middle of Montreal Island, the St. Lawrence River, and the business city center south of Mont Royal (see Fig. 1). At the local scale, the urban landscape near the measurement site should not contain large parks, water bodies, large parking lots, and highways, as well as buildings and trees taller than the typical roughness elements.

Following this guidance, a heavily populated area located in the Rosemont/Petite-Patrie district in the eastern part of Montreal (see Fig. 1), typically correspond- 


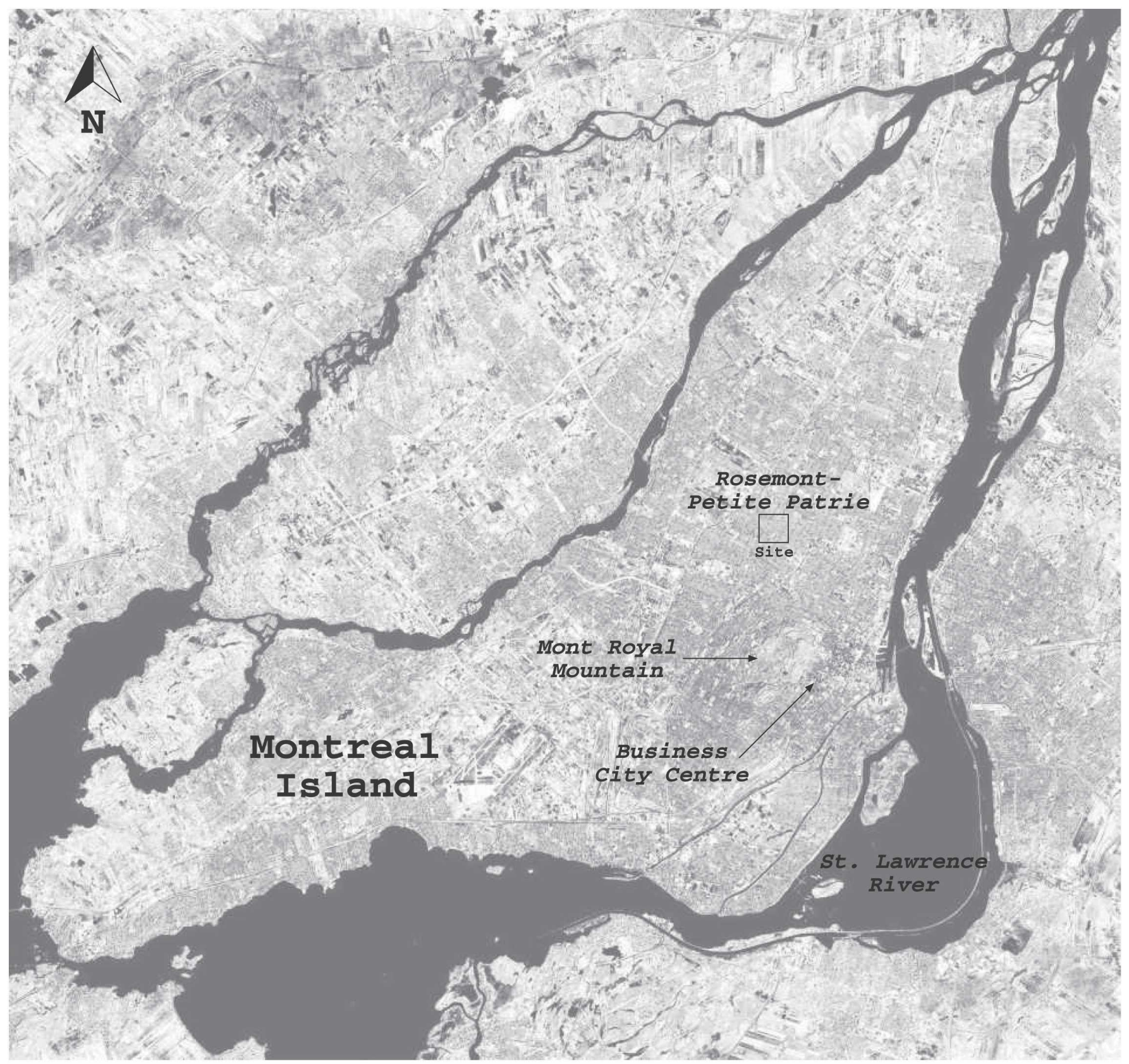

FIG. 1. Space-based photograph of Montreal and its surrounding areas. Source: Landsat-7 satellite image.

ing to UCZ 3 in Oke's (2004) classification, was selected for the campaign. The aerial photograph of the site (Fig. 2) reveals the homogeneity and the regular arrangement of the urban landscape, that is, a succession of rectangular blocks composed of adjacent houses with backyards and front yards overlooking the street. These blocks are oriented from northwest to southeast with alternating streets and alleys. Most of the buildings are two- or three-story houses with flat roofs and small backyards (Fig. 2). These houses are alike in terms of geometric characteristics and material properties. The mean building height is approximately $9.5 \mathrm{~m}$. The walls are mostly made of bricks while the roofs and roads are made of asphalt. Table 1 gathers all the descriptive parameters of the UCZ derived from aerial photograph analysis for several representative blocks of the area. Figure 3 presents a schematic diagram of the study area.

There are several small parks around the site, the nearest one being $150 \mathrm{~m}$ to the north. The others are more than $500 \mathrm{~m}$ to the west, southeast, and northeast. Only two buildings (to the north and to the west) are taller than the houses of the chosen district and could constitute obstacles to the flow. Thus, despite some anomalies, the surface characteristics of the district are homogeneous, particularly for northwesterly, southwesterly, southerly, and easterly flows. As shown by the 


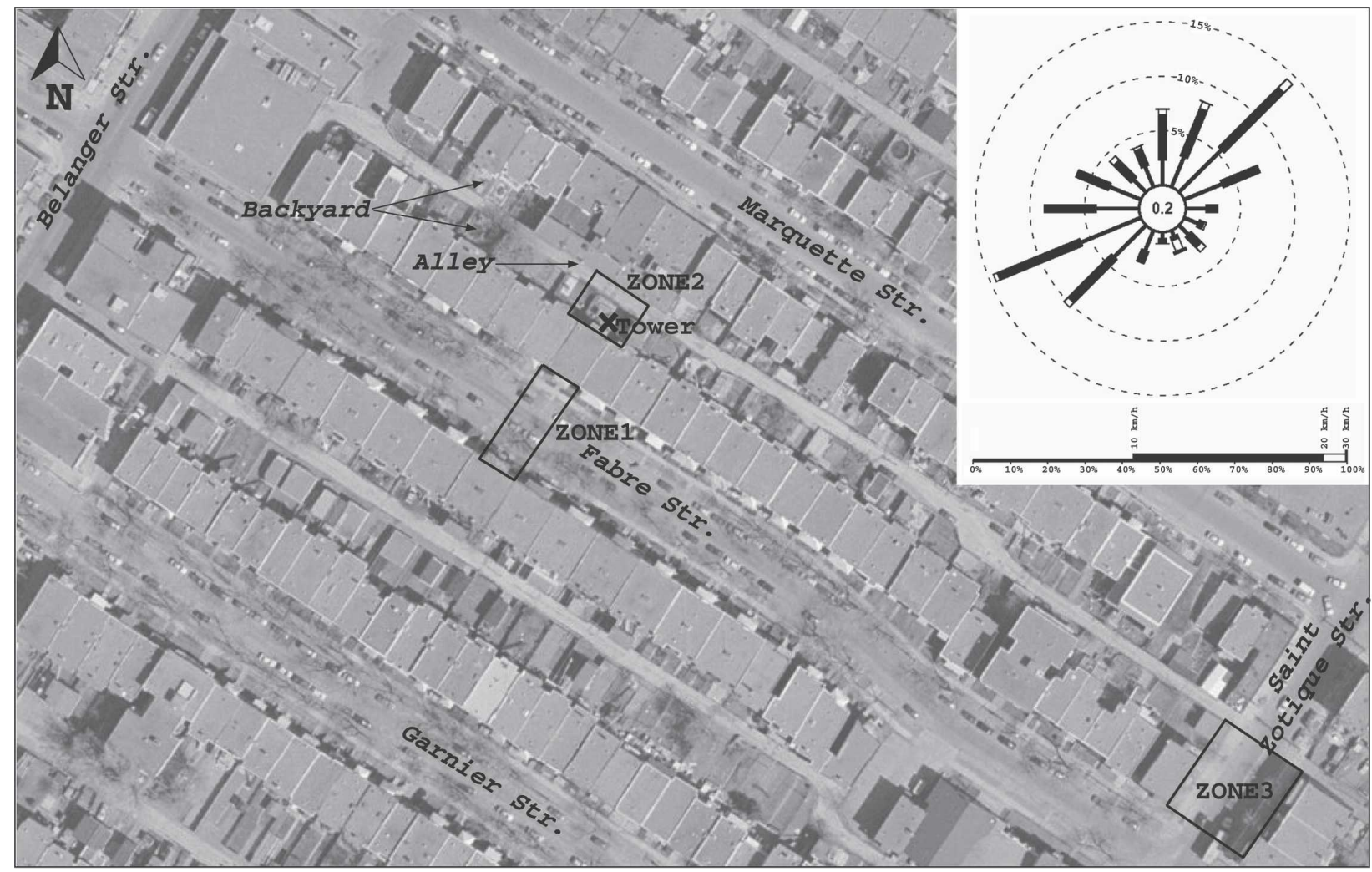

FIG. 2. Aerial photograph of the study site. The wind rose chart (top right) is computed using the wind measurements collected during the MUSE observation period. Source: Navigateur Urbain, city of Montreal (http://www.navurb.com).

wind rose chart (Fig. 2) obtained during MUSE using a wind monitor installed at the top of the tower (instrumentation presented in section $3 \mathrm{a}$ ), the most frequent wind directions observed during the campaign are northeasterly, southwesterly, and west-southwesterly. Considering the aerial photograph and the location of the anomalies, the most favorable synoptic condition is a southwesterly flow. A complete analysis of the turbulent flux footprints will be presented in section $4 \mathrm{~b}$ in order to evaluate the validity and consistency of the data collected during the campaign.

\section{Instrumentation and measurements}

MUSE was conducted between 17 March to 14 April 2005 (henceforth denoted as MU076-104, according to the day of the year). During the experiment, a large part of the instrumentation functioned continuously, while other measurements could not be done automatically with fixed observation systems and required manual sampling strategy. Such measurements were only conducted during IOPs, which are indicated on the calendar of the field campaign given in Fig. 4. This calendar also points to other significant events during the campaign, such as rainfall and fog events during which the turbulent flux measurements were not reliable, and periods when the instrumented tower was lowered because of strong winds or in order to clean the sensors.

\section{a. Automatic measurements}

The main feature of the observation site was a crankup 20-m tower mounted on a 5-m-long trailer located in a backyard of Fabre Street (see Figs. 2 and 5), $4.7 \mathrm{~m}$ away from the house. The radiometer, the infrared camera, and the instrumentation required for the tur-

TABle 1. Description of the district.

\begin{tabular}{lcl}
\hline \multicolumn{1}{c}{ Covers } & Fractions $(\%)$ & \multicolumn{1}{c}{ Properties } \\
\hline Pervious covers & 29.2 & \\
Backyards & 20.3 & Lawns + trees \\
Front yards & 8.9 & Lawns \\
Impervious covers & 70.8 & \\
Roofs & 35.5 & Asphalt \\
Sidewalks & 14.8 & Concrete \\
Roads & 15.4 & Asphalt \\
Alleys & 5.1 & Concrete \\
\hline
\end{tabular}




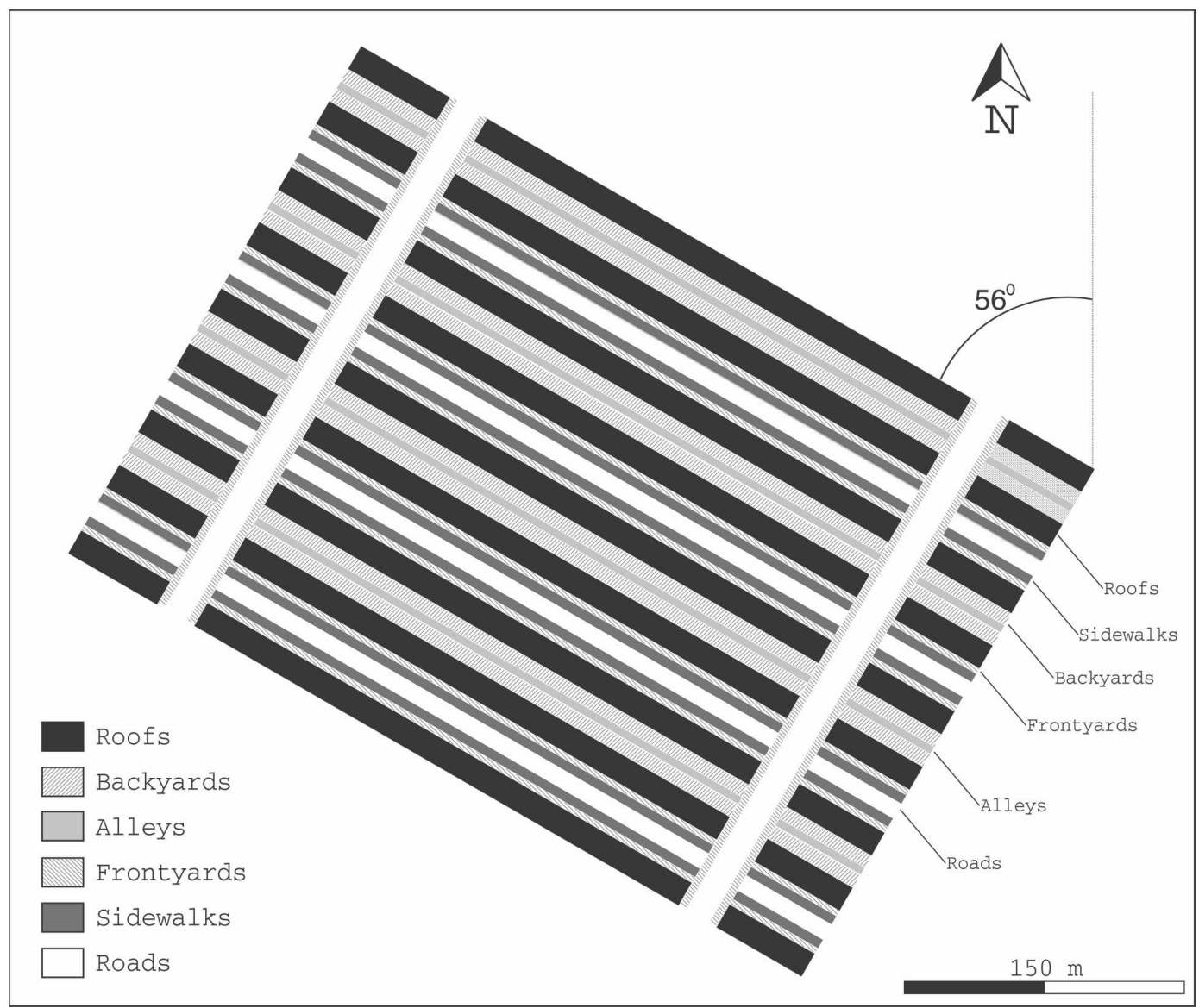

FIG. 3. Sketch of the urban climate zone based on aerial photo analysis (without taking parks into account).

- MARCH 2005 -

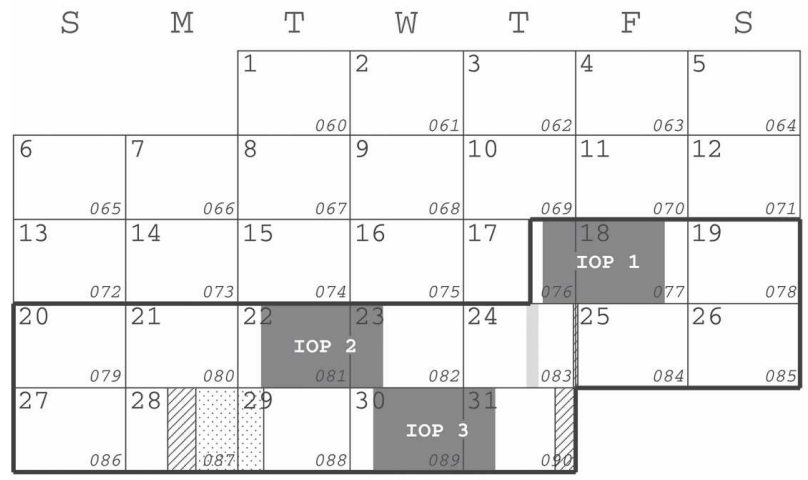

- APRIL 2005 -

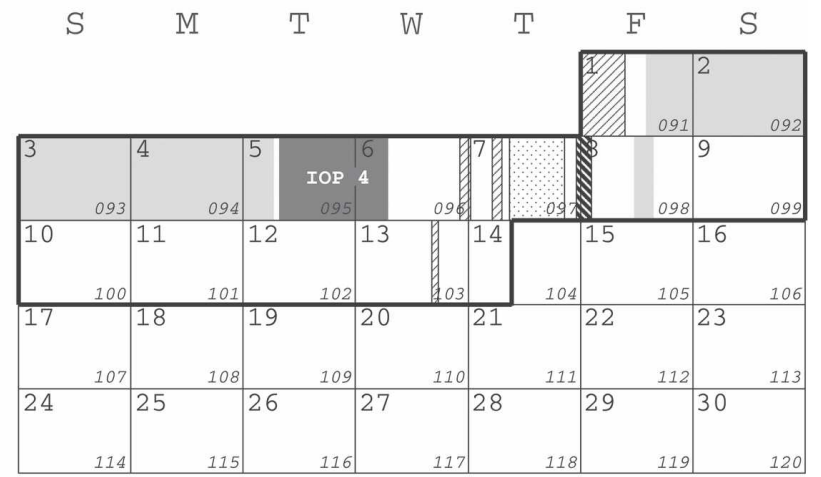

\begin{tabular}{|l|}
\hline Observational period \\
IOP \\
Tower down
\end{tabular}

FIG. 4. Timetable of the campaign with indications of the meteorological conditions (day of the year for 2005 is labeled in italics). 

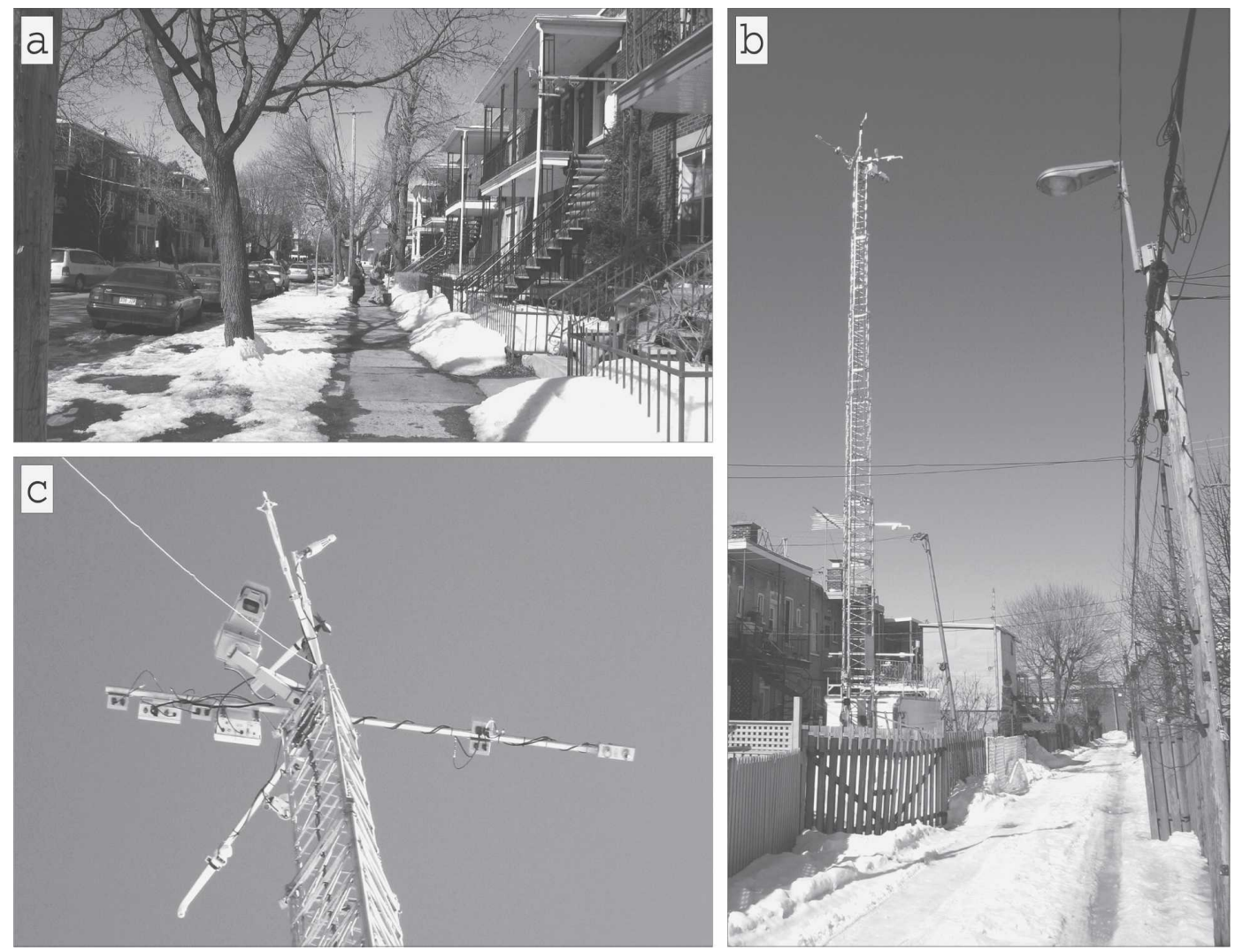

FIG. 5. Photographs of the study area and the instrumentation. (a) Fabre Street looking northwest, (b) alley looking northwest and backyard where the tower was installed, and (c) zoom of the instrumentation mounted at the top of the tower and described in Table 3.

bulent flux measurements (sonic anemometer, open path $\mathrm{CO}_{2}$ and $\mathrm{H}_{2} \mathrm{O}$ analyzer) were installed at the top of tower (Fig. 5). Two fine wire thermocouples were also fixed to the tower at two different levels. The setup of the instrumentation is described in Fig. 6, and the details on the instruments are summarized in Table 2.

The net radiometer measured 5-min averages of longwave $(L)$ and shortwave $(S)$ downward $(\downarrow)$ as well as upward $(\uparrow)$ radiation. It was located at the top of the tower, $19.8 \mathrm{~m}$ above ground level (AGL). The sonic anemometer recorded the three components of the wind velocity $(u, v, w)$ and the friction velocity $\left(u_{*}\right)$ at $21.0 \mathrm{~m}$ AGL. At the same level, the open path $\mathrm{CO}_{2}$ and $\mathrm{H}_{2} \mathrm{O}$ analyzer collected the carbon dioxide and water vapor concentrations, and a fine wire thermocouple measured air temperature. In addition, a wind monitor was installed $22.0 \mathrm{~m}$ AGL. Observations of wind speed, concentration, and temperature fluctuations were stored at $10 \mathrm{~Hz}$ in order to compute the turbulent fluxes using the eddy covariance technique. According to Oke (2004), the turbulent flux measurements must be conducted above the roughness sublayer (RSL) in order not to be influenced by the microscale surface anoma- lies. The blending height $\left(z_{r}\right)$ corresponding to the top of the RSL is estimated to about $1.5 z_{H}$ (with $z_{H}$ being the mean height of the roughness elements) for dense and homogeneous urban districts. For the MUSE experiment, $z_{H}=9.5 \mathrm{~m}$ (section 2). Therefore, the tower measurements were done well above the top of the RSL.

The infrared camera, fixed near the top of the tower (Figs. 5 and 6), was oriented toward the roofs (i.e., toward Fabre Street). Its footprint mainly contains roofs together with the west side of Fabre Street, that is, the west part of the roadway and the opposite sidewalk. In addition to the infrared camera, two fixed infrared thermometers were installed in Fabre Street and in the alley, aimed at the first-story brick wall on each side of the house. The infrared thermometers recorded point measurements, whereas the camera documented the spatial variability by providing fields of radiative surface temperature. The camera can also be used to deduce the snow covers on roof, road, and sidewalk surfaces, considering the temperature differences between snow-covered surfaces and surfaces without snow. The fixed network was supplemented during IOPs by 
TABLE 2. Characteristics of the instrumentation.

\begin{tabular}{|c|c|c|c|}
\hline Variable & Instrument & Model & Location \\
\hline \multicolumn{4}{|l|}{ Automatic measurements } \\
\hline$S^{\downarrow}, L^{\downarrow}, S^{\uparrow}, L^{\uparrow}$ & Radiometer & Kipp \& Zonen CNR1 & Tower $19.8 \mathrm{~m}$ \\
\hline$u, v, w, u_{*}$ & 3D sonic anemometer & Campbell Scientific CSAT3 & Tower $21.0 \mathrm{~m}$ \\
\hline $\mathrm{CO}_{2}, \mathrm{H}_{2} \mathrm{O}$ & Open path $\mathrm{CO}_{2} / \mathrm{H}_{2} \mathrm{O}$ analyzer & Licor LI-7500 & Tower $21.0 \mathrm{~m}$ \\
\hline Wind direction and speed & Wind monitor & R. M. Young 05305 & Tower $22.0 \mathrm{~m}$ \\
\hline$T_{\text {air }}$ & Fine wire thermocouple & Campbell Scientific ASPTC & Tower 7.1, $19.8 \mathrm{~m}$ \\
\hline$T_{\text {air }}, \mathrm{RH}_{\text {air }}$ & Temperature and humidity probe & Campbell Scientific HMP45C & $\begin{array}{l}\text { Tower } 3.8,19.8 \mathrm{~m} \\
\text { Balcony } 4.4 \mathrm{~m}\end{array}$ \\
\hline$T_{S}$ & IR thermal imagery & MikroScan 7302 & Tower $19.8 \mathrm{~m}$ \\
\hline$T_{S}$ & IR thermometer & Raynger MI & $\begin{array}{l}\text { Tower } 3.8 \mathrm{~m} \text { (back wall) } \\
\text { Balcony } 4.4 \mathrm{~m} \text { (front wall) }\end{array}$ \\
\hline $\begin{array}{l}d_{\text {snow }} \\
\text { Manual measurements }\end{array}$ & Remote sensor & Campbell Scientific SR50 & Roof \\
\hline$T_{S}$ & Portable IR temperature sensor & Raynger MX4 & \\
\hline$\alpha$ & Pyranometers back to back & LI-200SA & \\
\hline$d_{\text {snow }}$ & Snow sampler & Mount Rose & \\
\hline$\rho_{\text {snow }}$ & Snow sampler & Mount Rose & \\
\hline
\end{tabular}

manual surface temperature records (see next section), enabling an intercomparison of the instruments.

Fabre Street and the alley were also instrumented with two stations recording 5-min averages of air temperature and air humidity inside the street canyons (Fig. 6). According to Nakamura and Oke (1988) and Vachon (2001), the sensors must be located at least $1 \mathrm{~m}$ away from walls and roads in order to observe the signature of the local urban environment and not the mi- croscale influence of the street. During MUSE, the sensor overlooking the street was fixed with a metallic arm to the first floor balcony, that is, $4.4 \mathrm{~m} \mathrm{AGL}$ and $3.1 \mathrm{~m}$ away from the wall. The other sensor, overlooking the alley, was fixed in the same manner to the tower $3.8 \mathrm{~m}$ AGL and $6.5 \mathrm{~m}$ away from the wall.

The snow was documented on one roof, that is, the roof of the house nearest the tower location (Fig. 6). Since the roofs of the district are all flat and have simi-

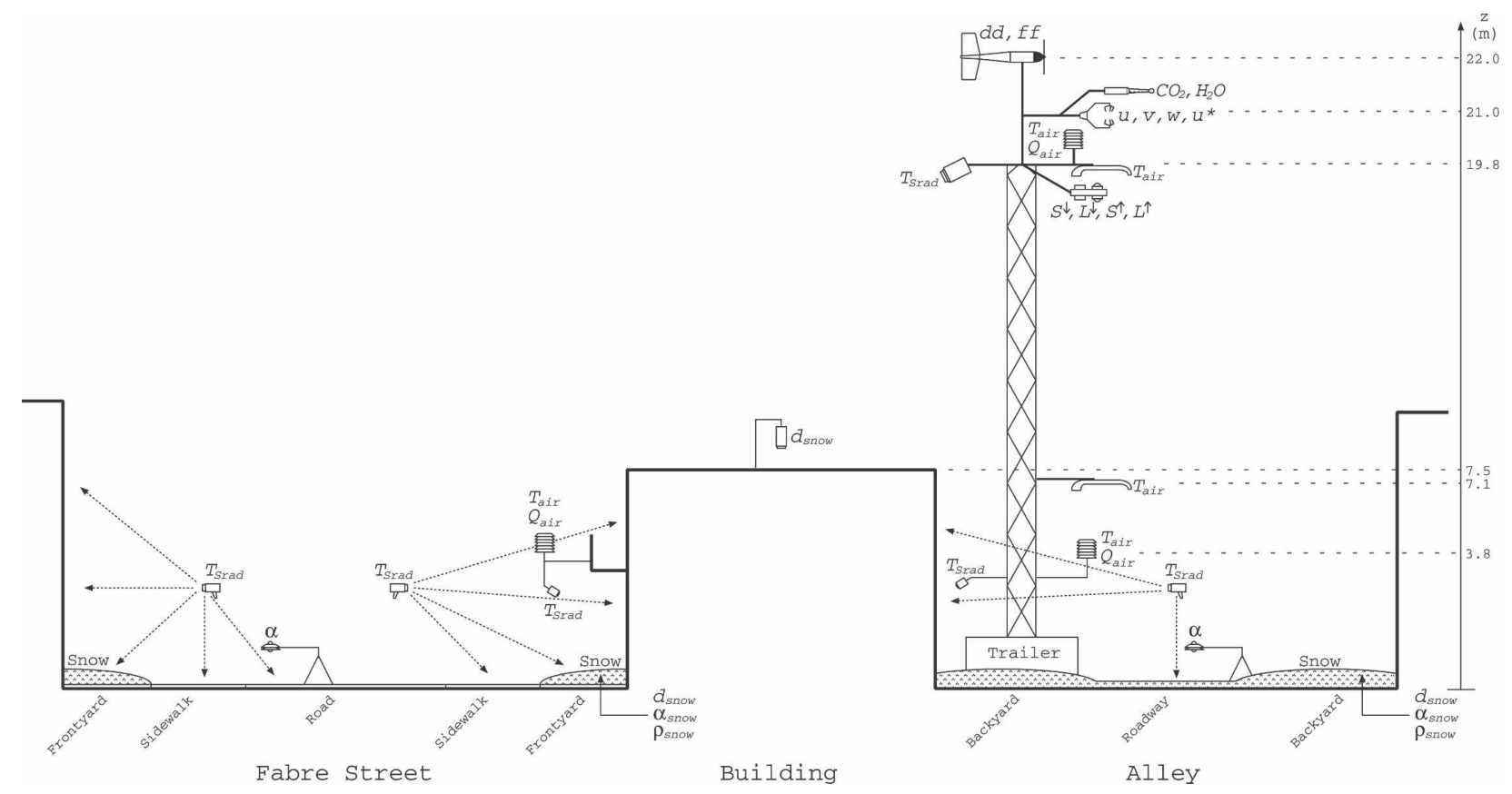

FIG. 6. Diagram of the fixed instrumentation installed in Fabre Street and in the alley (looking northwest), as well as of the manual observations of surface temperature, albedo, and snow properties conducted in the same areas. 
lar material properties, it seems reasonable to assume that the snow cover is relatively homogeneous. The insulation systems as well as the habits of heating can, however, vary from one house to another and induce differences of snow cover on the roofs. In order not to disturb the radiation and energy balances (and also for safety reasons), only a remote sensor was installed to record 5-min averages of snow depth. Also, to avoid accumulation effects on the edges, the measurements were done in the middle of the roof.

\section{b. Intensive observational periods}

Four IOPs were conducted in MUSE (Fig. 4) during favorable meteorological situations, that is, with clear sky and southwesterly wind conditions (see section 2). Each of those IOPs documented one full daily cycle by starting either before sunrise at 0500 local standard time (LST) or before sunset at 1700 LST. The first three IOPs covered $26 \mathrm{~h}$ of continuous observations, and the last IOP covered $23 \mathrm{~h}$. A rigorous observational protocol was followed during the IOPs, which included manual measurements at specific times of radiative surface temperatures and snow properties in addition to the measurements taken by the automatic (fixed) observational setup.

Surface temperatures were measured by operators at every hour. To take the complexity of the urban canopy into account, the measurements were conducted at three different locations close to the tower site (Fig. 2): Fabre Street (zone 1) oriented southeast to northwest, the alley (zone 2) east of Fabre Street (same orientation), and Saint-Zotique Street (zone 3) oriented southwest to northeast. This strategy aimed at covering the two main street orientations of the UCZ, and at simultaneously documenting streets and alleys that have different characteristics, notably for the snow cover. It should be noted that these targeted zones are comparable within the whole UCZ in terms of urban arrangement, geometry, and materials.

Various samples of urban facets were identified to document the spatial variability of surface temperatures (Fig. 6). For the walls, independent measurements were carried out for windows and brick facets, at different stories. In the streets, sampling was done on sidewalks, the middle of the road, and the front yard. Since there was no snow removal in the alley, the ground condition was homogeneous and only one surface temperature was done in the middle of the alley. To generate a consistent database, the same sampling locations were documented for all the IOPs.

For urban areas, thermoradiative fields are variable. They strongly depend on the thermal and radiative properties of the materials, on the orientation of the urban facet itself, and on the orientation and shape of the street canyons. The surface temperatures also vary spatially for a given facet because of shadow effects and radiation reflections. An example of manually collected surface temperatures of various urban facets recorded during IOP1 is presented in Fig. 7, in which this thermoradiative variability is well illustrated. During daytime, the sunshine effects are preponderant. The southwestern wall gets much warmer because it is exposed to the sun, whereas the northeastern wall stays in the shadow all day long. Thus, the surface temperature reaches almost $30^{\circ} \mathrm{C}$ for the southwestern wall, while it does not exceed $2^{\circ} \mathrm{C}$ for the northeastern wall, corresponding more or less to the air temperature inside the street. Similarly, the southwestern sidewalk and roadway indicate an important rise of temperature during the day, also due to sun exposure. Last, the surface temperature of snow accumulated on the front yard increases in the morning and is maintained around $0^{\circ} \mathrm{C}$ between 0900 and 1800 LST. During the night, the surface temperatures are negative, except for the southwestern wall during the first part of the night (until 0000 LST).

Another important aspect of manual measurements is related to the daily evolution of snow cover properties in the streets, which were documented every $4 \mathrm{~h}$ during daytime. Both snow depth and snow density were measured where snow accumulation was sufficient, that is, on the front yards of Fabre Street and on the edges of the alley (Fig. 6). Elsewhere (roadways and sidewalks), snow was usually removed almost completely after snowstorms and was rapidly degraded and compacted by pedestrians and cars, which made snowrelated measurements very difficult (if not impossible) during the experiment. The snow albedo was measured at the same locations. To supplement the documentation of the district, albedos of asphalt roads, as well as wet and dry sidewalks were also measured. Last, photographs of Fabre Street, Saint-Zotique Street, and the alley were taken regularly to evaluate the evolution of the snow cover on front yards, sidewalks, and roadways.

\section{Radiation and turbulent flux footprints}

Experimentally, radiation and turbulent fluxes are not estimated in the same manner. Down- and upwelling radiation are directly measured by a radiometer, while the sensible $\left(Q_{H}\right)$ and latent $\left(Q_{E}\right)$ heat fluxes are computed using the eddy covariance technique (see section 3a). Consequently, their respective footprints are not the same and do not depend on the same effects and processes. The present section pro- 


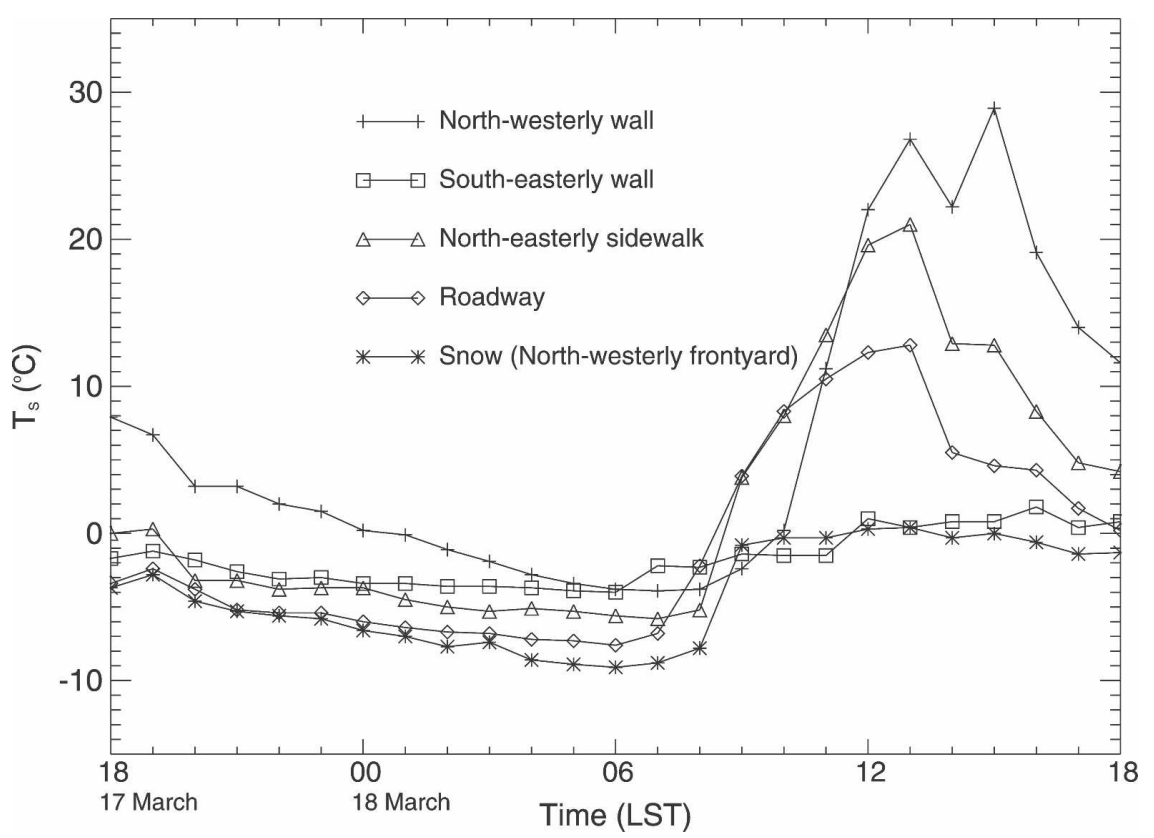

FIG. 7. Surface temperatures recorded manually during IOP1 (17-18 Mar 2005) for various urban facets.

poses an evaluation of these different footprints and investigates the relevance and quality of the flux database collected during the experiment.

\section{a. Upward radiation footprints}

The area seen by the radiometer, oriented toward the ground, and measuring the upward radiation, is directly connected to the radiative footprint of the sensor. The latter depends not only on the position and height of the instrument but also on the geometry of the urban canopy beneath. Obviously, the radiative footprint is larger if the radiometer is located higher up. It is composed of contributions from urban and nonurban facets, that is, roads (sidewalks and roadways), roofs, walls, gardens, and front yards. Each of them may be partially sunlit and shaded according to the obstruction effects and the position of the sun.

The surface-sensor-sun urban model (SUM) was developed by Soux et al. (2004) in order to determine what surfaces are seen by the radiometer for a known angular field of view (FOV) and a specific urban landscape. SUM uses a geographic information system (GIS) describing the geometry and arrangement of the urban canopy. The position, height, and angular FOV of the radiometer are defined as input parameters. The current version of SUM allows the urban canopy to be defined as a combination of four types of elements: roofs, walls, roads, and alleys. Forced by incoming solar radiation (determined according to the date and hour of the day), the model computes the fractions of sunlit and shaded surfaces of roofs, walls, roads, and alleys seen by the sensor.

In the present case, the study area is more complex than what is presently accommodated by SUM, since it is composed of roofs, front yards, sidewalks, roadways, alleys, and backyards (see Figs. 4 and 5). To fit the urban arrangement of the district to the SUM input parameters, front yards, sidewalks, and roadways are merged into the SUM's element roads, while backyards and alleys are gathered in the element alleys. The model of the district used by SUM is based on a simplified version of Fig. 3 and on the geometric parameters of Table 1 . The radiometer is assumed to be located $20 \mathrm{~m}$ AGL and $5 \mathrm{~m}$ away from the wall in the backyard. SUM is run one day per week from 0600 to 1800 LST with a 3 -h time step for the five weeks of the experiment. The hemispheric view of the net radiometer is approximated with a $170^{\circ} \mathrm{FOV}$ in the SUM model.

Figure 8 presents the cumulated fractions (sunlit + shadow fractions) of walls, roads, alleys, and roofs seen by the radiometer, which exclusively depend on the urban canopy geometry and on the position of the instrument. The tower being located in the backyard, the main contribution comes from the alleys $(44.5 \%)$. The radiometer also sees an important proportion of roofs $(29.1 \%)$, since it is fixed at the top of the tower above the urban canopy. Last, the walls represent $24.9 \%$ of 

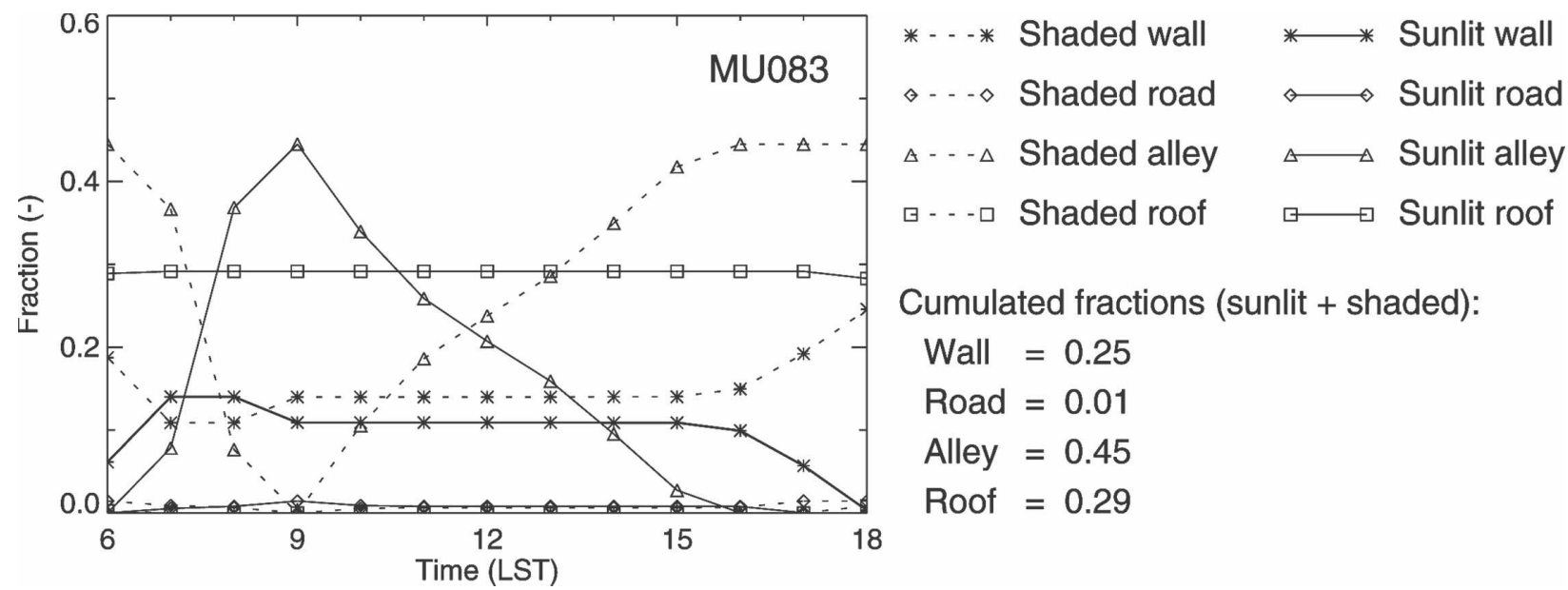

Cumulated fractions (sunlit + shaded):

Wall $=0.25$

Road $=0.01$

Alley $=0.45$

Roof $=0.29$

FIG. 8. Diurnal evolution of sunlit and shaded fractions of the various urban and nonurban surfaces seen by the radiometer on MU083. The cumulated sunlit and shaded fractions are also indicated.

what is seen, and the roads only $1.5 \%$. The very low contribution of the roads is explained by the near-total obstruction caused by the buildings for the radiometer.

For each type of elements the partitioning between sunlit and shaded surface contributions varies with the hour of the day. Considering the experiment only lasted one month, the daily cycle of the various contributions does not vary too much from one week to another. The results obtained with SUM are presented on one day (MU083) selected randomly from the study period (Fig. 8). Since the roofs are flat in the study area, there is no obstruction effect for the sensor that only sees sunlit roofs. The contribution of the sunlit and shaded walls (vertical facets) directly varies with the sun's zenith position. The walls are mainly shaded at 0600 and 1800 LST because the zenithal angle is too large, but the partitioning between sunlit and shaded fractions is very similar between 0900 and 1500 LST. Contributions of roads and alleys are strongly influenced by the azimuthal angles. Between 0900 and 1200 LST, the azimuthal angle is almost the same as the street direction, which limits the obstruction by walls. As a result, alleys and roads seen by the radiometer are almost entirely sunlit. In the morning and the evening, when the azimuthal angle is nearly perpendicular to the street orientation, these surfaces are completely shaded.

Using the simplified version of the UCZ sketch (Fig. 3 ), the "real" fractions of each element can be computed and compared with the cumulated cover fractions seen by the radiometer. For the UCZ, walls, roads, alleys, and roofs represent $33.5 \%, 26.1 \%, 16.8 \%$, and $23.6 \%$, respectively, relative to the complete area (i.e., plane + vertical surfaces). The fractions of roofs and walls seen by the radiometer are comparable to the real fractions. The cumulated contribution of plane surfaces on the ground (alleys + roads) is also reasonable ( $46.0 \%$ versus $42.9 \%$ ), but the partitioning is largely unbalanced to the benefit of the alleys.

The elements seen by the radiometer do not necessarily contribute to the upward radiation measured by the instrument in the same proportions as their view factor. On one hand, the longwave upward radiation recorded by the sensor depends on the radiation emitted by the various surfaces. Consequently, it is mainly driven by the surface temperatures. On the other hand, shadow effects and reflections inside the urban canopy can decrease or increase the quantity of shortwave radiation intercepted and reflected by each element, and then received by the radiometer. For instance, if shaded surfaces are considered not to contribute to the upward shortwave radiation (because they do not intercept direct downward shortwave radiation), then the fractions have to be recomputed only by taking the sunlit parts into account and by normalizing them (Fig. 8). In this case, the road and wall contributions stay similar to those obtained by considering both sunlit and shaded parts. But roof and alley contributions vary much more according to the hours of sunshine of the alley. As the roofs are always in the sun, their contribution is maximum when the alleys are shaded (at sunset and sunrise) and minimum when the alley is in the sunshine (around 0900 LST).

In conclusion, the interpretation of these results is complex. Running a specific model of radiation solving the numerous processes that take place inside the urban canopy could help to better evaluate the various contributions. In any case, it turns out that the position of the radiometer during the experiment tends to overestimate the alley and roof contributions and underestimate the radiation emitted by the streets. This could 
TABLE 3. Mean fraction (\%) and associated std dev (\%) of various cover types included in turbulent flux footprints according to the four stability classes.

\begin{tabular}{llcccc}
\hline \hline & & & & & Very \\
& & Stable & Quasi-neutral & Unstable & unstable \\
\hline Roads & Mean & 34.4 & 33.7 & 34.6 & 34.6 \\
& Std dev & 15.4 & 34.0 & 4.8 & 2.4 \\
Buildings & Mean & 2.0 & 1.9 & 1.2 & 0.7 \\
& Std dev & 3.1 & 2.9 & 1.7 & 1.9 \\
Houses & Mean & 32.2 & 32.4 & 32.8 & 33.5 \\
& Std dev & 14.8 & 32.7 & 4.9 & 3.7 \\
Vegetation & Mean & 31.2 & 31.9 & 31.3 & 31.2 \\
& Std dev & 14.6 & 32.4 & 4.9 & 4.7 \\
\hline
\end{tabular}

have an impact on short- and longwave radiation measurements considering that snow cover is very different on roofs, in alleys, and on the streets. A more sophisticated version of SUM is needed in order to differentiate roofs, front yards, sidewalks, roadways, alleys, and backyards. This new description of the urban arrangement should help better quantify the effect of snow on the radiative measurements.

\section{b. Turbulent flux footprints}

Footprints of turbulent flux measurements are computed using the flux-source area model (FSAM) (Schmid and Oke 1990). They evolve spatially and temporally according to the wind and stability conditions (Schmid and Oke 1990; Grimmond and Oke 1991) at the instrument level. The FSAM input parameters include the Monin-Obukhov length $L$, the friction velocity $u_{*}$, the standard deviation of wind direction $\sigma_{v}$, the zero-plane displacement height $z_{d}$, the measurement height above the zero-plane displacement height $z_{m}$, and the roughness length for momentum $z_{0} ; L, u_{*}$, and $\sigma_{v}$ are calculated using measurements at the sensor level for the period MU076-104 with a 1-h time step. The estimation of $z_{d}$ and $z_{0}$ is based on Fig. 1 of Grimmond and Oke (1999a), with a dependence on wind direction and the frontal area index $\lambda_{F}$.

The hourly footprints are gathered by stability classes defined from the parameter $z_{m} / L$, that is, stable $\left(z_{m} / L>0.001\right)$, quasi-neutral $\left(0.001 \geq z_{m} / L \geq\right.$ $-0.001)$, unstable $\left(-0.001>z_{m} / L>-0.1\right)$, and very unstable $\left(z_{m} / L \leq-0.1\right)$ conditions. For each stability category, the surface characteristics of the cumulated footprints are analyzed. The fractions and associated standard deviations of the various types of covers (roads, railways, individual buildings, houses, vegetation, and water), presented in Table 3, are calculated using the National Topographic Data Base (NTDB) developed by Geomatics Canada. The occurrence fre- quency of the four stability classes indicates (not shown here) that stable and quasi-neutral conditions are systematically observed at nighttime when the turbulent flux contributions are very low. The impact of the surface variability is much more important during daytime, corresponding to unstable and very unstable conditions. The footprints, computed for these two stability classes, are shown in Fig. 9, superimposed on the NTDB.

According to Table 3, the cover fractions associated with unstable and very unstable conditions are consistent and homogeneous. The roads, houses (two- and three-story houses), and vegetation (parks and backyards) each cover approximately one-third of the footprints with a low temporal variability. The individual buildings, corresponding to public or commercial buildings higher and larger than the typical houses, represent a negligible fraction of the domain. As a result, the ground contribution to the turbulent flux measurements remained homogeneous during the observational period irrespective of wind direction (Fig. 9). Under some wind and stability conditions, however, the footprints can temporarily contain a significant fraction of green areas, which could affect the turbulent flux measurements. This is discussed in the next section.

\section{Radiation and energy balances}

In the present case, the energy balance $\left(\mathrm{W} \mathrm{m}^{-2}\right)$ can be written

$$
Q^{*}+Q_{F}=Q_{H}+Q_{E}+\Delta Q_{S}+Q_{M}+\Delta Q_{A}
$$

This equation is based on the energy balance equation expressed by Oke (1987) with $Q^{*}$ net all-wave radiation, $Q_{F}$ anthropogenic heat flux, $Q_{H}$ sensible heat flux, $Q_{E}$ latent heat flux, $\Delta Q_{S}$ storage heat flux, and $\Delta Q_{A}$ net advective heat flux. For the study period, it must however include an additional term $\left(Q_{M}\right)$ that refers to the energy sink associated with the snowmelt process or the energy source when water freezes in the snowpack and on the ground.

The net radiation is deduced from the components of the radiation balance, which are all directly measured by the radiometer, that is, $Q^{*}=S^{\downarrow}+L^{\downarrow}-S^{\uparrow}-L^{\uparrow}$. The sensible and latent heat fluxes are computed using the eddy covariance technique. Considering the spatial homogeneity of the experimental site (presented in section $4 \mathrm{~b}$ ), the net advective heat flux is neglected. Last, $Q_{F}, \Delta Q_{S}$, and $Q_{M}$ cannot be measured directly. These different contributions can be gathered together in the residual term of the energy balance $\left(Q_{\text {Res }}=\right.$ $\left.Q^{*}-Q_{H}-Q_{E} ; \mathrm{W} \mathrm{m}^{-2}\right)$ as 


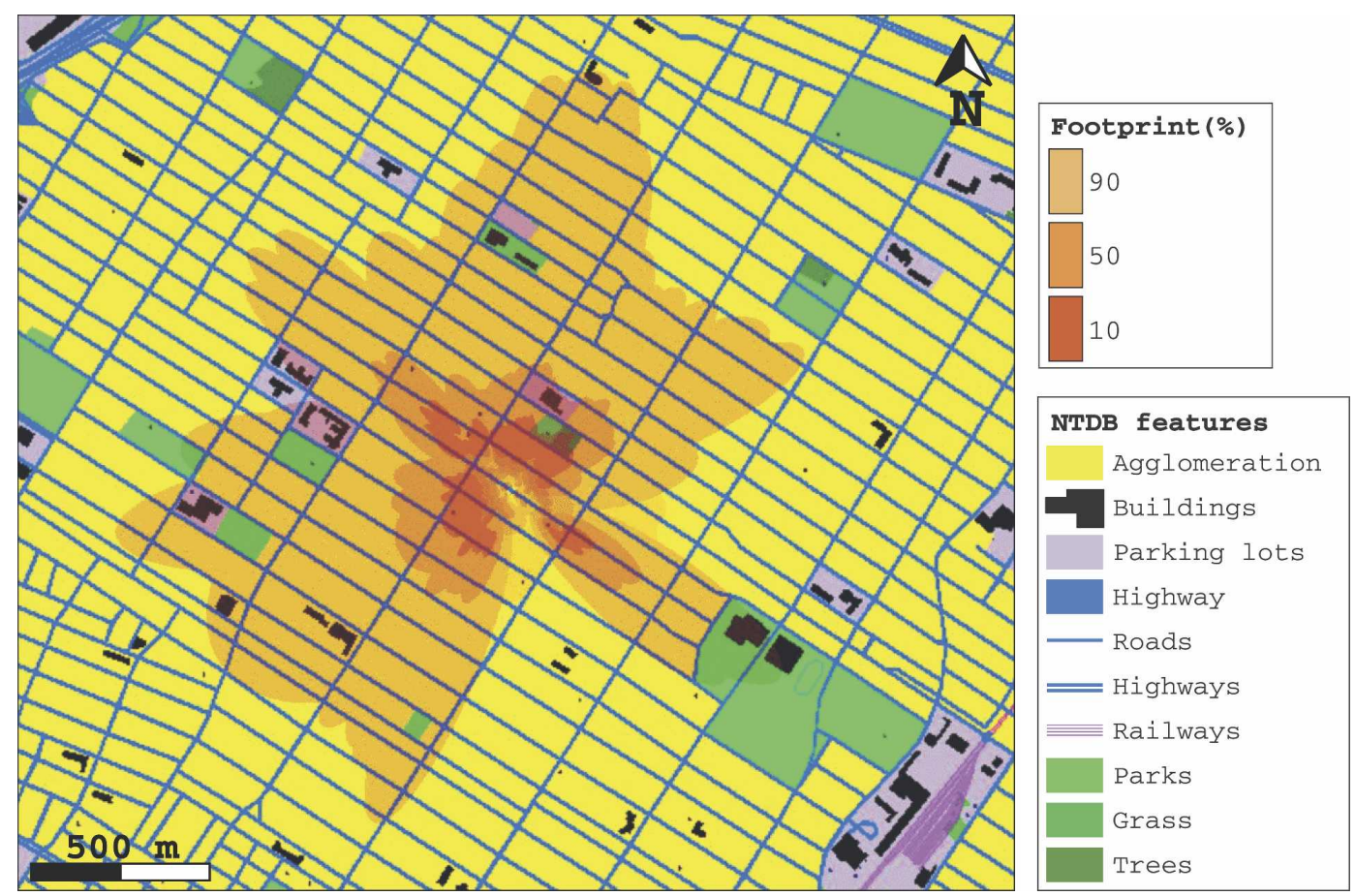

FIG. 9. Cumulated footprints of turbulent fluxes, calculated with FSAM for unstable and very unstable conditions for the study period. The three tones of orange correspond to areas that contribute for $10 \%, 50 \%$, and $90 \%$ of the turbulent flux measurement. In the background, the NTDB database represents the main urban features of the domain.

$$
Q_{\text {Res }}=\Delta Q_{S}+Q_{M}-Q_{F} .
$$

Note that over snow the latent heat flux has to be calculated using the latent heat of sublimation instead of the latent heat of evaporation. In the present case, however, the observed latent heat flux includes contributions coming from snowpacks in the streets, in alleys, and on the roofs, but also from wet surfaces. These different terms are difficult to quantify and evolve during the campaign. Contribution from the snowpack is preponderant early in the experiment, but decreases rapidly as the snow melts. Since the latent heat of evaporation and sublimation are equal to 2.500 and $2.835 \mathrm{MJ} \mathrm{kg}^{-1}$, respectively, the latent heat flux can vary from $12 \%$ maximum according to the case. Since $Q_{E}$ remains very weak during the field campaign, this variation never exceeds $7-8 \mathrm{~W} \mathrm{~m}^{-2}$, which is considered as negligible. The latent heat fluxes presented afterward are computed using the latent heat of evaporation.

\section{a. Averaged radiation and energy balances}

Figure 10 presents the radiation and energy balances averaged over the whole period MU076-104 with a 1-h time step. According to the radiation balance, this pe- riod (March-April) is characterized by a large incident solar radiation (almost $800 \mathrm{~W} \mathrm{~m}^{-2}$ of downward shortwave radiation at noon) and a net radiation reaching $540 \mathrm{~W} \mathrm{~m}^{-2}$. The energy balance displays very low values of latent heat fluxes (not exceeding $30 \mathrm{~W} \mathrm{~m}^{-2}$ ) although vegetation covers more than $29 \%$ of the area (Table 1). The sensible heat flux reaches about $200 \mathrm{~W}$ $\mathrm{m}^{-2}$ at daytime, but becomes slightly negative at night from 2000 LST. As seen in Fig. 10, the residual term is significant. The contributions of $Q_{H}, Q_{E}$, and $Q_{\mathrm{Res}}$ averaged for the daytime period $\left(Q^{*}>0\right)$ represent respectively $38 \%, 6 \%$, and $56 \%$ of $Q^{*}$ (see Table 4 ), and the Bowen ratio $\left(\beta=Q_{H} / Q_{E}\right)$ is 6.30 . The integral of the residual term for the whole period of MUSE (daytime and nighttime) remains positive $\left(+40 \mathrm{~W} \mathrm{~m}^{-2}\right)$.

These results are compared with the energy balances observed at the urban site referred to as $\mathrm{U} 2$ in Basel (Christen and Vogt 2004) and the Lipowa site in Łódź (Offerle et al. 2006) for spring period. These three sites have very comparable characteristics, that is, about $30 \%$ of vegetation fraction, between $30 \%$ and $35 \%$ of building fraction, and mean building heights from 9 to $12 \mathrm{~m}$. Here $Q_{H} / Q^{*}, Q_{E} / Q^{*}, Q_{\mathrm{Res}} / Q^{*}$, and $\beta$ estimated for Basel and Łódź are similar: 0.50, 0.18, 0.32, and 3.18 for Basel against 0.49, 0.12, 0.39, and 3.96 for Łódź. This 

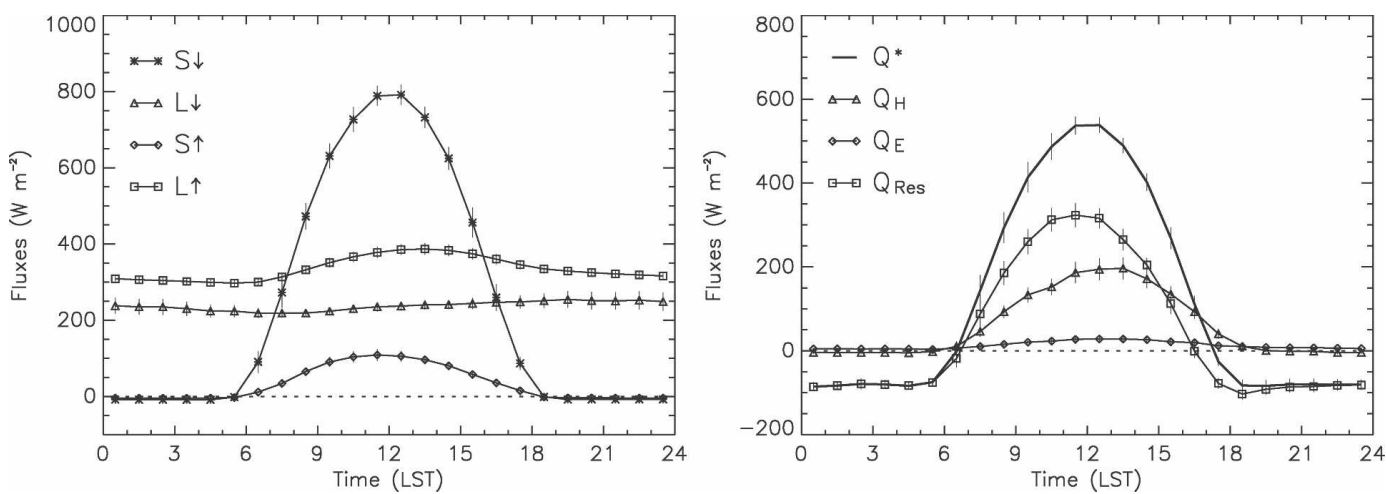

FIG. 10. (a) Mean radiation and (b) energy balances observed during MU076-MU104. The vertical bars represent the standard deviations $\left(\mathrm{W} \mathrm{m}^{-2}\right)$ of the fluxes.

corresponds to greater turbulent heat flux contributions than in MUSE associated with a lower residual term contribution. It should also be noted that the Bowen ratio is almost two times larger for MUSE than for the two other experiments. This issue is probably explained by the climate and snow cover differences between Montreal and the European cities of Basel and Łódź. Their climatologies for March-April present much larger temperatures than in Montreal, and the weather data indicate that there is no longer snow at this period. As a result, the vegetation is not active yet in Montreal, whereas the evapotranspiration already plays a considerable role in Basel and Łódź energy balances in spring.

\section{b. Effect of flow characteristics}

It is worth noting that the energy balance varies from day to day, according to the meteorological situations. First, the variations of wind and stability conditions during the course of the experiment influence the turbulent flux measurements. Second, the solar radiative forcing gradually increases during spring and is associated with an increase in air temperature, which favors the snowmelt and influences the energy exchanges.

To illustrate the variability of the energy balance associated with meteorological forcing, the first panel of Fig. 11 shows the temporal evolution of the energy balance for four successive days (from MU078 to MU081) at the beginning of the campaign when snow cover is still significant. Net radiation remains very similar for each day of this short period, but its partitioning between turbulent and residual fluxes varies considerably. On MU078, the energy balance is comparable to the averaged energy balance displayed in Fig. 10; that is, $Q_{\text {Res }}, Q_{H}$, and $Q_{E}$ reach maxima of about 300, 200, and $50 \mathrm{~W} \mathrm{~m}^{-2}$, respectively. On MU079 and MU080, the contribution of sensible heat flux largely decreases (less than $25 \%$ of the net radiation during daytime, instead of $39 \%$ on MU078) to the benefit of the residual term (about $70 \%$, instead of $51 \%$ ). The latent heat flux is also smaller, only contributing for $6 \%$ of $Q^{*}$ versus $10 \%$ previously. The energy balance observed on MU081 indicates similar contributions of $Q_{H}$ and $Q_{\text {Res }}$ around $45 \%$ of $Q^{*}$, when $Q_{E}$ represents $10 \%$ of $Q^{*}$ as on MU078.

Analysis of the flow characteristics is useful in trying to understand these differences observed for the first few days of the experiment. The wind direction and wind speed for the same period (Fig. $11 \mathrm{~b}$ and c) display some modifications of the flow. It is observed that wind is from west-southwest $\left(225^{\circ}\right)$ on MU078, then from the north $\left(360^{\circ}\right)$ on MU079 during daytime and from west-southwest in the evening. During the night of MU080, the low-level wind comes from the east $\left(90^{\circ}\right)$, from the west-southwest in the evening, and then keeps this same orientation on MU081. In addition, the wind speed is lower when the wind blows from north and east

TABLE 4. Mean daytime $\left(Q^{*}>0\right)$ values of the energy balance components and mean daytime partitioning for the whole period (MU076-MU104), for a typical period with snow (MU077-MU080), and for a period with a near-zero snow cover (MU099-MU101).

\begin{tabular}{lccc}
\hline & Mean & With snow & Without snow \\
\hline & $\begin{array}{c}\text { MU076- } \\
\text { MU104 }\end{array}$ & $\begin{array}{c}\text { MU077- } \\
\text { MU080 }\end{array}$ & $\begin{array}{c}\text { MU099- } \\
\text { MU101 }\end{array}$ \\
\hline$Q^{*}\left(\mathrm{~W} \mathrm{~m}^{-2}\right)$ & +347 & +337 & +389 \\
$Q_{H}\left(\mathrm{~W} \mathrm{~m}^{-2}\right)$ & +132 & +107 & +170 \\
$Q_{E}\left(\mathrm{~W} \mathrm{~m}^{-2}\right)$ & +21 & +26 & +16 \\
$Q_{\text {Res }}\left(\mathrm{W} \mathrm{m}^{-2}\right)$ & +194 & +204 & +202 \\
$Q_{H} / Q^{*}$ & 0.38 & 0.32 & 0.44 \\
$Q_{E} / Q^{*}$ & 0.06 & 0.08 & 0.04 \\
$Q_{\text {Res }} / Q^{*}$ & 0.56 & 0.60 & 0.52 \\
$\beta$ & 6.30 & 7.82 & 10.39 \\
\hline
\end{tabular}



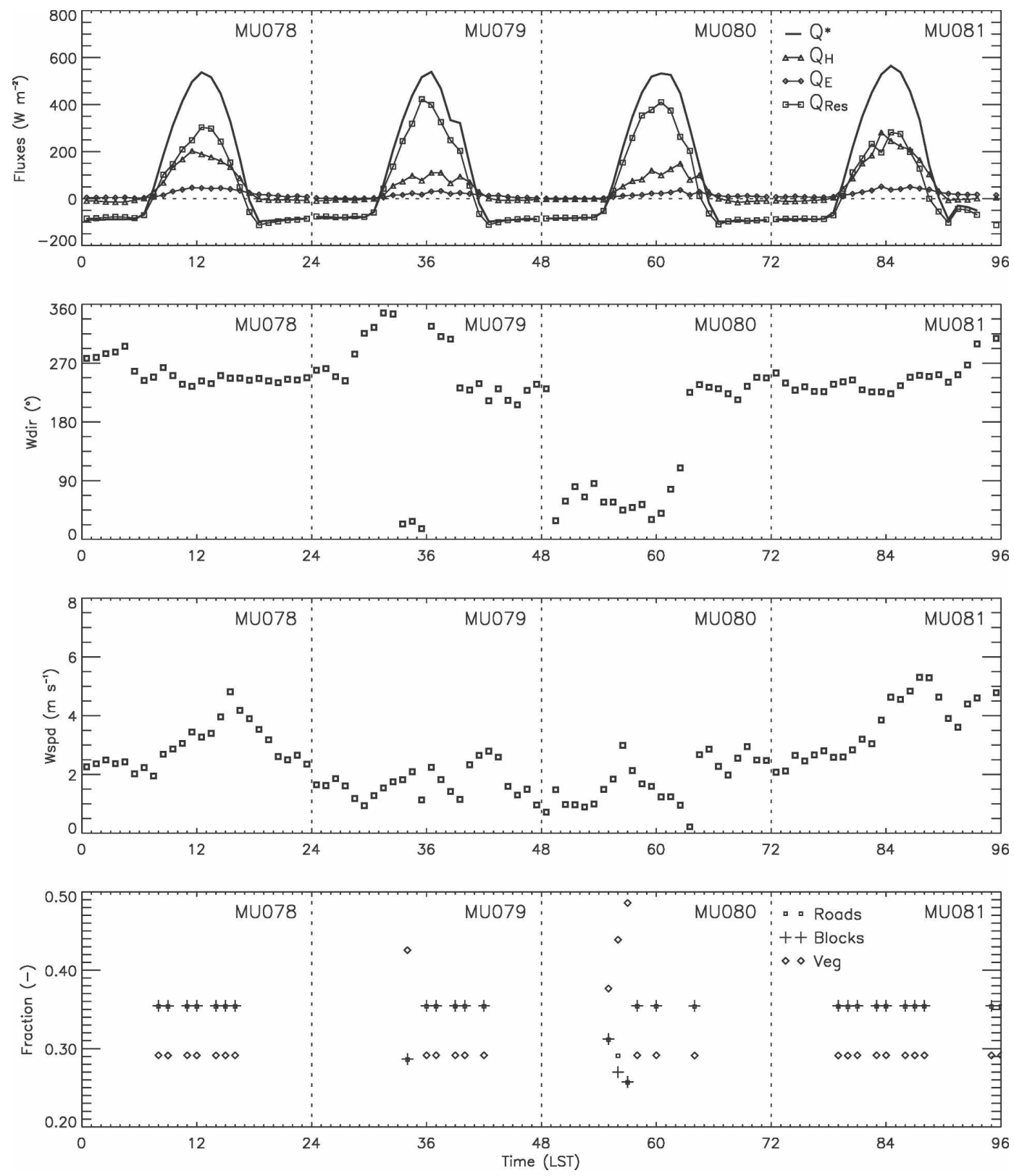

FIG. 11. (a) Energy balance observed for four successive days early in the field experiment (from MU078 to MU081). (b) The wind direction and (c) wind speed recorded by the wind monitor, and (d) cover fractions of roads, blocks, and vegetation computed with FSAM.

than when it blows from west-southwest. The last panel of Fig. 11 shows the cover fractions of roads, blocks, and vegetation associated with the turbulent footprints calculated using the FSAM model (see section $4 \mathrm{~b}$ ). While the fractions remain nearly constant on MU078 and MU081 and similar to the averaged values presented in Table 3, the vegetation fraction increases significantly for some hours of the day on MU079 and MU080, indicating that the footprints include areas covered by parks.
It seems from these results that the decrease of $Q_{H}$ and the increase of $Q_{\text {Res }}$ noticed on MU079 and MU080 are linked to flow changes (Fig. 11). First, the weakening of the wind tends to limit the sensible heat flux production. Second, the wind rotation induces a spatial variation of the turbulent footprint. In the particular case when the turbulent source area includes parks, the net radiative forcing associated with this area decreases because parks are mainly snow-covered and absorb less solar radiation, because of high albedo of snow. As a 

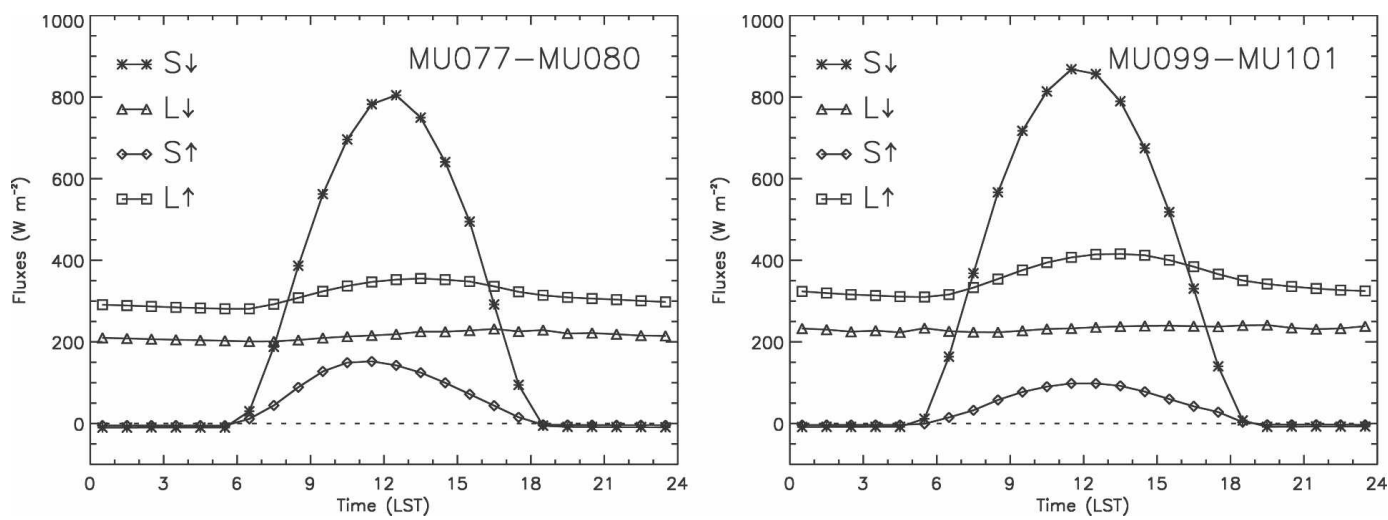

FIG. 12. Mean radiation balance observed during (a) MU077-MU080 with a near-complete snow cover, and during (b) MU099-MU101 with a near-zero snow cover.

result, less energy is available to produce sensible heat flux. In addition, because the radiation footprint does not contain any parks (see section $4 \mathrm{a}$ ), its associated net radiation is greater than the one corresponding to the turbulent footprint. Since $Q_{\text {Res }}$ is computed using $Q^{*}$ deduced from the radiometer measurements, this term tends to be overestimated in the energy balance, which could explain the high contribution of $Q_{\text {Res }}$ observed on MU079 and MU080. This large increase of $Q_{\text {Res }}$ may also be associated with a more important contribution of the snowmelt when the source areas include vegetation since the parks are greater snow reservoirs than the urban surfaces. Last, the increase of $Q_{H}$ on MU081 is probably due to the intensification of the wind speed when the flow comes again from west-southwest.

\section{c. Impact of radiative forcing variations}

During the field campaign, both solar radiation and air temperature increase through the period of observations, leading to complete snowmelt and an absence of snow on the ground at the end of the measurement period. The radiation and energy balances observed at the beginning of the experiment with a large snow cover (averaged on MU077-MU080), and at the end of the experiment with a quasi-zero snow cover (averaged on MU099-MU101) are compared in Figs. 12 and 13. The evolution of the radiation balance (Fig. 12) is mainly associated with a decrease of $S^{\uparrow}$ and an increase of $L^{\uparrow}$ during daytime; $S^{\uparrow}$ is particularly large on MU077-MU080 because of the important snow cover, which contributes to increase the mean albedo. With the progressive snowmelt during the experiment, $S^{\uparrow}$ decreases, and $L^{\uparrow}$ tends to increase because of increased surface temperatures.

The energy balance (Fig. 13) also significantly changes during the experiment. The net radiation $Q^{*}$ is larger during MU099-MU101 than during MU077MU080, since the incident radiation increases while the upward shortwave radiation decreases, as discussed above. The average daytime partitioning of the energy balance is presented in Table 4. During the experiment, the latent heat flux tends to decrease because the main contribution to $Q_{E}$ comes from the presence of snow on the ground. On MU099-MU101, this term represents only $4 \%$ of the net radiation. The contribution of $Q_{H}$ increases $(44 \%$ instead of $32 \%$ ), while that of the residual term decreases ( $52 \%$ instead of $60 \%$ ). The diurnal cycle is also different for the two periods MU077MU080 and MU099-MU101. The energy balance on MU099-MU101 is much more representative of the energy balances usually observed in densely built-up areas, for example, Mexico City (Oke et al. 1999), Basel (Christen and Vogt 2004), Marseille (Grimmond et al. 2004a), and Łódź (Offerle et al. 2006). In particular, it is characterized by hysteresis of $Q_{\mathrm{Res}}$ and $Q_{H}$ in relation to $Q^{*}$ (not shown); $Q_{\text {Res }}$ reaches its maximum in the morning, whereas $Q_{H}$ reaches it in the afternoon. In addition, a slightly positive $Q_{H}$ is observed during the first part of the night. In contrast, the energy balance on MU077-MU080 does not display any hysteresis, since both $Q_{\text {Res }}$ and $Q_{H}$ reach their maximum values around noon. In conclusion, the presence of snow in an urban environment has a significant impact on the magnitude of the turbulent fluxes and the residual term, as well as on their diurnal cycles. This can be explained by the effect of the snow itself but also by the additional anthropogenic heat fluxes. An analysis of these different factors is currently in progress.

\section{Conclusions}

The MUSE is an original study that investigates, for the first time, the thermoradiative exchanges in a very 

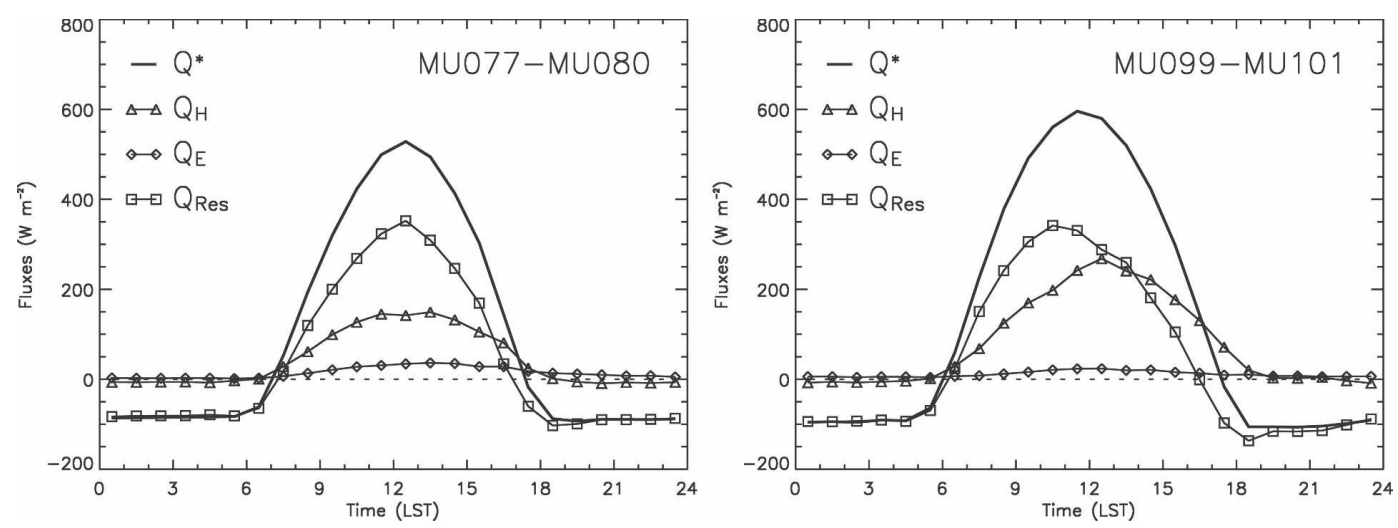

FIG. 13. Mean energy balance observed during (a) MU077-MU080 with a near-complete snow cover, and during (b) MU099-MU101 with a near-zero snow cover.

densely built-up area in late winter and spring conditions, with special emphasis on snow conditions. A complete database has been collected to improve our understanding of urban processes during wintertime and under cold conditions.

Computations with the SUM model of the radiometer footprint for upward radiation underline the difficulty of correctly locating this type of instrument in urban environments, so that the sensor "sees" a representative combination of urban and nonurban facets. In MUSE, the location of the tower in a backyard likely induces an overestimation of upward radiation measurements in comparison with the roads' contribution. This imbalance surely affects the short- and longwave upward radiation recorded by the radiometer, considering that snow cover is very different on roads and alleys.

The surface characteristics, associated with turbulent flux footprints estimated from FSAM for unstable conditions, remain fairly homogeneous during the observational period except for a few short episodes when the source area includes parks. The energy balance averaged for the entire observation period shows the importance of the residual term, which exceeds $50 \%$ of the net radiation, in contrast with sensible and latent heat flux contributions, which represent less than $40 \%$ and $10 \%$, respectively. The flux partitioning and the daily pattern of the energy balance, however, were found to depend on flow characteristics. Under specific wind conditions (in particular, northerly and easterly flows), the impact of surrounding green areas on the experimental energy balance is underlined. For these situations, differences in the radiative and turbulent footprints become apparent because of spatial variations in urban snow cover that lead to a potential mismatch between the observed net radiation and that which is actually forcing the measured turbulent fluxes.
Snow cover and snowmelt processes also influence the radiation balance and the energy exchanges measured during the experiment, leading to a decrease of the latent heat flux and an increase of the sensible heat flux. With the disappearance of the snow, the diurnal cycles of $Q_{H}$ and $Q_{\text {Res }}$ change and start to exhibit a hysteresis. A detailed study is currently being conducted in order to evaluate the different contributions to the energy balance coming from anthropogenic heat emissions, snowmelt, and heat storage in the urban structures.

Last, the observational database is of major interest for urban modeling applications. A specific urban canopy model, the Town Energy Balance (TEB; Masson 2000), has been recently included in the physics package of the Global Environmental Multiscale (GEM) and the Mesoscale Compressible Community (MC2) Canadian atmospheric models. TEB has already been tested for various urbanized areas such as the Mexico City center and a light-industrial district of Vancouver (Masson et al. 2002), the Marseille city core (Lemonsu et al. 2004), and a residential area in Ouagadougou (Offerle et al. 2005), in each case under warm, sunny, and dry meteorological conditions. Within the framework of the MSC's urban research program (Mailhot et al. 2006), MSC plans to develop a version of TEB optimized and adapted to the specifics of Canadian cities and Canadian climate. In particular, the model must be able to simulate a realistic urban microclimate under cold and snowy conditions. In this context, MUSE provides a complete and relevant dataset that will make possible an original evaluation of the model. Specific attention will be paid to the quality of the snow cover parameterization in urban environments.

Acknowledgments. Thanks are given to Tim Oke and Sue Grimmond for their expert advice in the site selec- 
tion and observation program design. We are grateful to Stavros Antonopoulos, Najat Benbouta, Olivier Gagnon, and Radenko Pavlovic for their dedicated work during IOPs, to Alain Robichaud for coining the MUSE acronym, and to the Morneau family for granting access to this unique site on Fabre Street. The support of MSC management, in particular Gilbert Brunet and Richard Hogue, is warmly acknowledged. This work is funded by the Chemical, Biological, Radiological and Nuclear (CBRN) Research and Technology Initiative (CRTI) (Project 02-0093RD) of Defence R\&D Canada.

\section{REFERENCES}

Bélair, S., J. Mailhot, A. Lemonsu, M. Benjamin, F. Chagnon, G. Morneau, and R. Hogue, 2006: The Montreal Urban Snow Experiment (MUSE). IAUC Newsletter, No. 16, International Association for Urban Climate, 9-10. [Available online at http://www.urban-climate.org.]

Christen, A., and R. Vogt, 2004: Energy and radiation balance of a central European city. Int. J. Climatol., 24, 1395-1421.

Coutts, A. M., J. Beringer, and N. J. Tapper, 2007: Impact of increasing urban density on local climate: Spatial and temporal variations in the surface energy balance in Melbourne, Australia. J. Appl. Meteor. Climatol., 46, 477-493.

Grimmond, C. S. B., and T. R. Oke, 1991: An evapotranspirationinterception model for urban areas. Water Resour. Res., 27, 1739-1755.

$\longrightarrow$, and -1995 : Comparison of heat fluxes from summertime observations in the suburbs of four North American cities. J. Appl. Meteor., 34, 873-889.

$\longrightarrow$, and - 1999a: Aerodynamic properties of urban areas derived from analysis of surface form. J. Appl. Meteor., 38, 1262-1292.

$\ldots$, and $-1999 \mathrm{~b}$ : Rates of evaporation in urban areas. Impacts of Urban Growth on Surface and Ground Waters, IAHS Publication 259, 235-243.

— I. A. Salmond, T. R. Oke, B. Offerle, and A. Lemonsu, 2004a: Flux and turbulence measurements at a densely builtup site in Marseille: Heat, mass (water and carbon dioxide), and momentum. J. Geophys. Res., 109, D24101, doi:10.1029/ 2004JD004936.

- H.-B. Su, B. Offerle, B. Crawford, S. L. Scott, S. Zhong, and C. Clements, 2004b: Spatial variability of heat fluxes in a suburban area of Oklahoma City. Preprints, Fifth Symp. on Urban Environment, Vancouver, BC, Canada, Amer. Meteor. Soc., 3.11.

Ho, C. L. I., and C. Valeo, 2005: Observations of urban snow properties in Calgary, Canada. Hydrol. Processes, 19, 459473.

Lemonsu, A., C. S. B. Grimmond, and V. Masson, 2004: Modeling the surface energy balance of the core of an old Mediterranean city: Marseille. J. Appl. Meteor., 43, 312-327.

Mailhot, J., S. Bélair, A. Lemonsu, L. Tong, A. Leroux, N. Ben- bouta, and R. Hogue, 2006: Urban modeling at the Meteorological Service of Canada. IAUC Newsletter, No. 17, International Association for Urban Climate, 13-16. [Available online at http://www.urban-climate.org.]

Masson, V., 2000: A physically-based scheme for the urban energy budget in atmospheric models. Bound.-Layer Meteor., 94, 357-397.

— C. S. B. Grimmond, and T. R. Oke, 2002: Evaluation of the Town Energy Balance (TEB) scheme with direct measurements from dry districts in two cities. J. Appl. Meteor., 41, 1011-1026.

— , and Coauthors, 2004: The Canopy and Aerosol Particles Interaction in Toulouse Urban Layer (CAPITOUL) experiment: First results. Preprints, Fifth Symp. on Urban Environment, Vancouver, BC, Canada, Amer. Meteor. Soc., 1.2.

Nakamura, Y., and T. R. Oke, 1988: Wind, temperature and stability conditions in an east-west oriented urban canyon. Atmos. Environ., 22, 2691-2700.

Offerle, B., P. Jonsson, I. Eliasson, and C. S. B. Grimmond, 2005: Urban modification of the surface energy balance in the West African Sahel: Ouagadougou, Burkina Faso. J. Climate, 18, 3983-3995.

— C. S. B. Grimmond, K. Fortuniak, K. Klisik, and T. R. Oke, 2006: Temporal variations in observed heat fluxes over a northern European downtown. Theor. Appl. Climatol., 84, 103-115.

Oke, T. R., 1987: Boundary Layer Climates. 2nd ed. Methuen, 435 pp.

_ 2004: Initial guidance to obtain representative meteorological observations at urban sites. World Meteorological Organization, Instruments and Observing Methods, IOM Rep. 81, WMO Tech. Doc. 1250, 51 pp.

_, R. A. Spronken-Smith, E. Jáuregui, and C. S. B. Grimmond, 1999: The energy balance of central Mexico City during the dry season. Atmos. Environ., 33, 3919-3930.

Rotach, M. W., and Coauthors, 2005: BUBBLE-An urban boundary layer meteorology project. Theor. Appl. Climatol., 81, 231-261.

Schmid, H. P., and T. R. Oke, 1990: A model to estimate the source area contributing to turbulent exchange in the surface layer over patchy terrain. Quart. J. Roy. Meteor. Soc., 116, 965-988.

Semádeni-Davies, A. F., and L. Bengtsson, 1998: Snowmelt sensitivity to radiation in the urban environment. Hydrol. Sci. J., 43, 67-89.

Soux, A., J. A. Voogt, and T. R. Oke, 2004: A model to calculate what remote sensor "sees" of an urban surface. Bound.-Layer Meteor., 111, 109-132.

Thorolfsson, S. T., and J. Brandt, 1996: The influence of snowmelt on urban runoff in Norway. Proceedings of 7 th International Conference on Urban Drainage and New Technology, C. Maksimovic, Ed., Elsevier Sciences, 309-316.

Vachon, G., 2001: Transferts des polluants des sources fixes et mobiles dans la canopée urbaine: Evaluation experimentale (in French). Ph.D. thesis, University of Nantes, France, 210 pp. 